\title{
Impactos de medidas de conservação de energia propostas no PBE Edifica para o nível de eficiência energética de envoltórias de um edifício naturalmente condicionado
}

Impacts of energy conservation measures proposed at the PBE Edifica for the energy efficiency level of envelopes of a naturally conditioned building

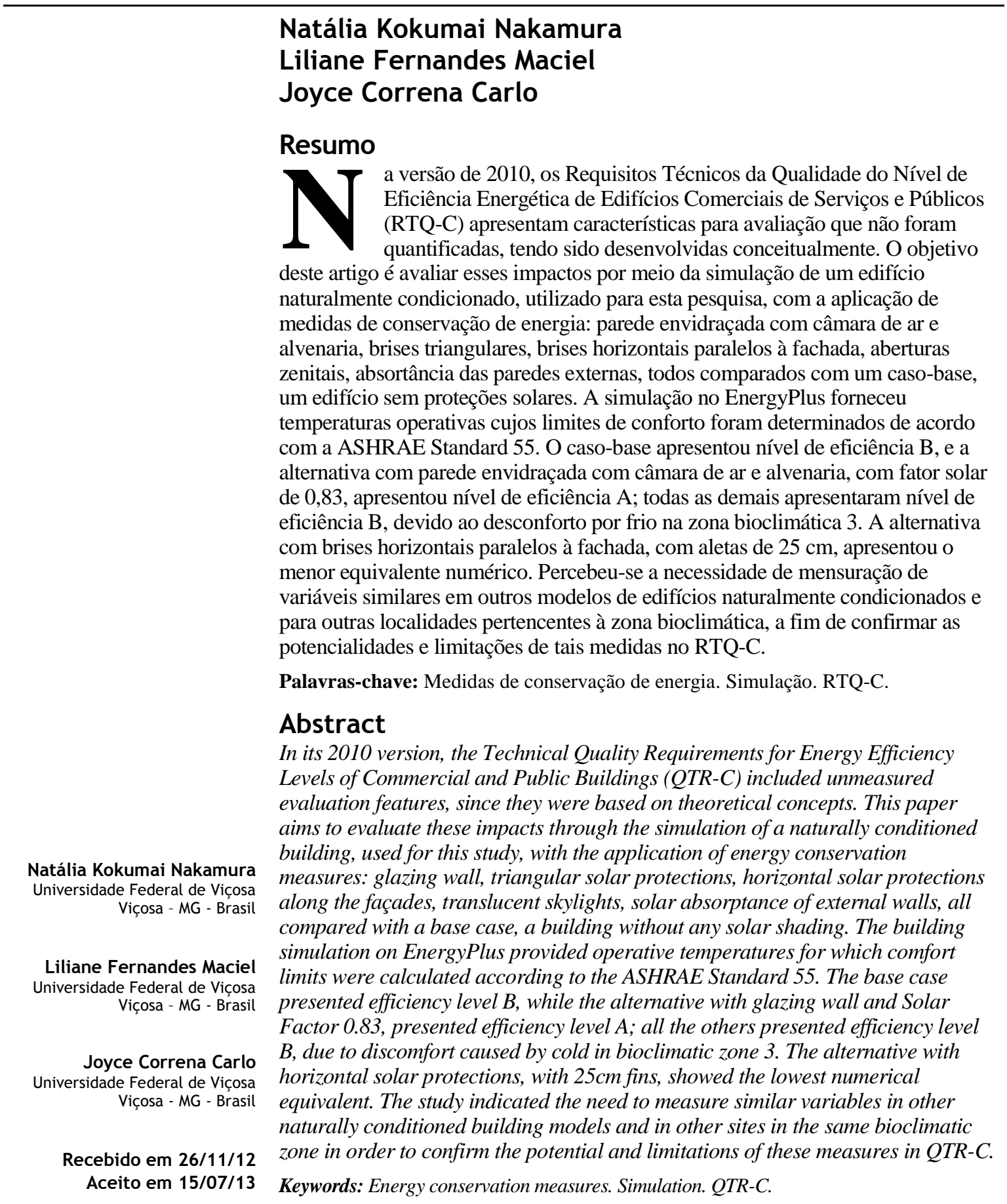




\section{Introdução}

Sabe-se que a tomada de decisões nos estágios iniciais de projeto arquitetônico tem impacto significativo na eficiência energética e desempenho interno dos edifícios (POLLOCK et al., 2009). A avaliação energética de edifícios estendida ao projeto, construção e vida útil, permite uma quantificação adequada das implicações de energia do edifício e, portanto, fornece a base para o planejamento adequado no setor (CASALS, 2006). A eficiência energética é um requisito a ser atendido para se alcançar a sustentabilidade que apresenta um grande potencial de aplicação em edifícios a partir da inovação e do desenvolvimento de melhorias na tecnologia aplicada aos sistemas construtivos. Sob esse aspecto, a criação de normas obrigatórias ajuda a racionalizar, na área de construção sustentável, o consumo de energia, reduzindo o desperdício (DIAZ; CZAJKOWSKI; CARROCCI, 2008).

A questão da eficiência energética vem ganhando relevância no mundo desde a década de 70 . Muitos países desenvolvem e aplicam programas que visam à redução do consumo de energia nos edifícios, que há muito deixou de ser exclusividade dos países líderes em políticas energéticas. Como exemplo, a Lituânia e a Irlanda, ambos países de clima frio, e Cingapura, de clima quente e úmido, têm seus próprios programas. O primeiro é baseado no desempenho para aquecimento e consumo de energia e, portanto, exclui o condicionamento para resfriamento (STANKEVICIUS; KARBAUSKAITE; MONSTVILAS, 2007), assim como o segundo (HERNANDEZ; BURKE; LEWIS, 2008). Já o último é voltado para edifícios condicionados artificialmente, com grande foco na demanda para resfriamento (LEE; RAJAGOPALAN, 2008). Vêse, com tais exemplos, que é raro encontrar programas de eficiência energética voltados a edifícios naturalmente condicionados, mesmo em países de climas mais quentes.

Em 2009, foi publicado o Regulamento Técnico da Qualidade do Nível de Eficiência Energética de Edifícios Comerciais, de Serviços e Públicos (RTQ-C), atualmente Requisitos Técnicos (INSTITUTO..., 2010), como parte do Programa Brasileiro de Etiquetagem (PBE) do Inmetro. Com o objetivo de estimular a construção de edificações eficientes do ponto de vista energético, ele classifica o nível de eficiência em uma escala crescente de $\mathrm{E}$ até o nível mais eficiente, A, para três sistemas básicos, envoltória, sistema de iluminação e sistema de condicionamento de $\operatorname{ar}^{1}$. O nível de eficiência pode ser determinado por dois métodos, o método prescritivo e o método de simulação. Entretanto, as envoltórias de edifícios ou ambientes naturalmente condicionados ${ }^{2}$ podem ser avaliadas apenas pelo método de simulação (INSTITUTO..., 2010).

A simulação computacional é uma abordagem técnica bastante relevante, pois permite a realização de análises paramétricas e a investigação de características não previstas no método prescritivo, bem como a investigação de algumas características já incluídas, mas cujo impacto no nível de eficiência da edificação ainda não foi quantificado. O método prescritivo dos Requisitos Técnicos da Qualidade do Nível de Eficiência Energética de Edifícios Comerciais, de Serviços e Públicos, o RTQ-C (INSTITUTO..., 2010), foi desenvolvido com base em simulações, principalmente seu item de envoltória (CARLO; LAMBERTS, 2008). Porém, após desenvolvido o método, novas medidas de conservação de energia foram incluídas sem que os impactos no desempenho do edifício fossem quantificados. Absortância de superfícies opacas e envidraçados sobre superfícies opacas da fachada são alguns exemplos incluídos como pré-requisitos da envoltória (INSTITUTO..., 2010). Não há dúvidas sobre a validade de tais abordagens, pois se baseiam em conceitos consolidados de conforto ambiental e eficiência energética. No entanto, sua mensuração é desejável tanto em edificações condicionadas naturalmente quanto artificialmente.

Desse modo, este artigo visa quantificar a influência de medidas de conservação de energia, tais como absortâncias de fachadas, proteções solares e iluminação zenital, no nível de eficiência da envoltória de uma edificação naturalmente condicionada por meio de simulação no EnergyPlus. Deve-se lembrar que o nível de eficiência da envoltória de edifícios naturalmente condicionados é obtido, segundo o RTQ-C (INSTITUTO..., 2010), por parâmetros de conforto do usuário do ambiente interno. Embora o método seja baseado no RTQ-C (INSTITUTO..., 2010),

\footnotetext{
${ }^{1}$ De acordo com os conceitos que embasaram a criação do RTQ$C$, os sistemas de condicionamento de ar ativos são considerados um dos três sistemas básicos da edificação (FOSSATI; LAMBERTS, 2010).

${ }^{2}$ Entende-se por edifício naturalmente condicionado aquele que não utiliza o condicionamento artificial. Consequentemente, ele é ventilado naturalmente, mesmo de modo precário. 0 termo "edifício naturalmente ventilado" não foi utilizado para evitar que tal edificação seja interpretada como um edifício com condições ideais de ventilação natural, pois a elegibilidade do edifício para avaliação é independente da concepção da ventilação interna.
} 
alguns procedimentos foram alterados, a fim de ampliar o escopo da análise, conforme justificado ao longo do artigo.

\section{RTQ-C}

\section{Medidas de conservação de energia}

Vários estudos são realizados a fím de quantificar a influência das decisões arquitetônicas em edificações e determinar recomendações de suporte a futuros projetos, de modo a aproximar as esferas acadêmicas e práticas, como realizado por Venâncio e Pedrini (2008) e Carlo e Lamberts (2008). A adoção de medidas de conservação de energia é fundamental, pois permite a redução do consumo de energia necessário para propiciar um mesmo nível de energia útil e possibilita o desenvolvimento de um estilo de vida que demande menos gastos, por meio do emprego de soluções alternativas e de novas tecnologias.

Pedrini et al. (2010) mostraram, por meio de simulações, que a classificação da envoltória pelo método prescritivo do RTQ-C (INSTITUTO..., 2010) pode deixar de contemplar soluções arquitetônicas de comprovada eficiência energética devido a simplificações na análise das variáveis da envoltória. De fato, o método prescritivo foi simplificado, a fim de abranger a grande maioria de edificações comerciais, de serviços e públicas existentes no país, cujas características não abrangem soluções diferenciadas. Tais soluções devem ser avaliadas pelo método de simulação computacional do desempenho termoenergético da edificação. E assim confirmaram Pedrini et al. (2010), ao mostrar o potencial do método de simulação computacional como ferramenta de análise do consumo energético de edifícios para suprir as limitações do método prescritivo. Salientaram, ainda, a importância das recomendações bioclimáticas desde as fases iniciais do projeto, como modo de assegurar o bom desempenho térmico e energético do edifício, que abrangem os edifícios naturalmente condicionados.

A simulação é o método mais completo para qualquer análise de desempenho térmico e/ou energético no RTQ-C (INSTITUTO..., 2010), por proporcionar flexibilidade nas opções que visam à racionalização do consumo de energia, que pode incluir o processo projetual. A simulação permite o estudo de edificações com volumetrias, aberturas ou proteções solares mais complexas; além disso, dispensa o atendimento aos diversos pré-requisitos do método prescritivo, independentemente do modo de condicionamento (INSTITUTO..., 2010).

Entre os programas computacionais que atendem aos pré-requisitos do método de simulação do regulamento, o EnergyPlus é adequado por atender a suas premissas básicas, ao utilizar o método do balanço térmico, recomendado pela ASHRAE e validado pelo método Bestest (AMERICAN..., 2004), e por apresentar um modelo de rede para ventilação natural para o ano completo (GU, 2007). Simula o desempenho térmico e energético de edificações, ao integrar sistemas relevantes para seu desempenho, tais como envoltória, climatização, iluminação artificial e natural, cargas internas e outros elementos que participam das trocas térmicas. Disponibiliza ferramentas e opções de simulação que permitem uma flexibilidade da modelagem de acordo com os objetivos da simulação, e seus recursos podem facilitar as análises posteriores devido ao grande número de dados de saída (CRAWLEY et al., 2008).

No RTQ-C (INSTITUTO..., 2010), a transmitância térmica, as cores e a absortância de superfícies opacas são consideradas pré-requisitos para a classificação do nível de eficiência energética da envoltória. Aberturas zenitais também são consideradas pré-requisitos, porém com limitações quanto ao fator solar (FS) máximo para percentuais de abertura zenital de até $5 \%$. Acima desse percentual, o regulamento exige a simulação computacional para se alcançar a classificação A ou B. Tais medidas foram avaliadas pelo método de simulação durante o desenvolvimento do RTQ$\mathrm{C}$ para edificações artificialmente condicionadas.

Outras características, como proteções solares, também foram quantificadas por simulação (CARLO; LAMBERTS, 2008), mas são avaliadas pelas equações de regressão que indicam o nível de eficiência da envoltória (CARLO; LAMBERTS, 2010a). Segundo Fossati e Lamberts (2010), elas são o segundo fator de influência na eficiência energética da envoltória pelo método prescritivo. Apesar de sua relevância, poucos tipos de proteções solares foram modelados, dada a variabilidade de possibilidades e orientações solares. Para aquelas que não tiveram os impactos mensurados, um método conceitual de obtenção de suas características foi proposto no RTQ-C para sua aplicação nas equações de avaliação da envoltória.

Santos e Souza (2012) já avaliaram algumas proteções solares horizontais conforme o RTQ-C com a simulação, mas não incluíram a análise sistemática das medidas de conservação de energia propostas pelo método conceitual. Para avaliar o método prescritivo, utilizaram a simulação em um edifício condicionado artificialmente e verificaram que os impactos no consumo foram de até $13 \% \mathrm{em}$ relação ao caso-base. Com esse resultado, indicaram haver uma pequena correspondência do 
método prescritivo com a realidade, ao contrário do mostrado por Fossati e Lamberts (2010). No entanto, os primeiros não quantificaram o nível de eficiência energética pelo método de simulação e, portanto, não se conhece o impacto da economia de $13 \%$ do consumo na classificação do edifício.

Além das proteções solares, a absortância solar de superfícies transparentes à frente de paredes opacas também não teve seu impacto mensurado para edifícios naturalmente condicionados. No RTQ-C, duas equações (Equação 1 - para vidros encostados à parede e Equação 2 - para vidros separados por câmara de ar da parede) são disponíveis para converter tal combinação, para se equivaler à absortância solar de superfícies opacas. Assim, as absortâncias solares de superfícies envidraçadas à frente de paredes opacas se tornam passíveis de avaliação pelo método prescritivo.

$\alpha=\alpha_{\text {vidro }}+\left(\tau_{\text {vidro }} \cdot \alpha_{\text {parede }}\right)$

Eq. 1

$\alpha=\mathrm{FS}_{\text {vidro }} \cdot \alpha_{\text {parede }}$

Eq. 2

Onde

$\alpha$ é a absortância solar;

$\tau$ é a transmitância solar; e

FS é o fator solar.

\section{Obtenção do nível de eficiência energética}

O método de simulação do RTQ-C para edifícios naturalmente condicionados exige que sejam obtidos índices de conforto determinados por uma das seguintes normas: EN 15251 (COMITÉ..., 2007), ISO 7730 (INTERNATIONAL..., 2005) ou ASHRAE Standard 55 (2010). Para esta última, devem-se obter as temperaturas operativas de cada ambiente (zona térmica) da edificação, além das temperaturas externas, para as 8.760 horas que compõem um ano completo. Em seguida, as condições de conforto devem ser analisadas de acordo com os critérios definidos pela norma. Ela considera que os usuários têm acesso a janelas operáveis e podem adaptar livremente suas roupas às condições térmicas locais. $\mathrm{O}$ cálculo consiste na determinação dos limites de conforto do ambiente interno com $\mathrm{o}$ uso de dados externos de temperatura do ar (AMERICAN..., 2010).
De posse desses limites, compara-se cada temperatura operativa do ambiente com os limites calculados hora a hora para aquele mês e aquela localidade, obtendo-se, assim, o percentual de horas ocupadas em condições de conforto térmico (POC) de cada ambiente (INSTITUTO..., 2010). A partir do POC é estabelecido o equivalente numérico de ventilação $\left(\right.$ EqNumV $\left._{\mathrm{amb}}\right)$ e o correspondente nível de eficiência de cada ambiente, de acordo com a Tabela $1^{3}$ (INSTITUTO..., 2010). De posse do equivalente numérico de ventilação de cada ambiente, é calculado o equivalente numérico total do edifício (EqNumV), por meio da média dos equivalentes numéricos dos ambientes ponderada pela área de cada ambiente (INSTITUTO..., 2010).

\section{Método de pesquisa}

\section{Definição do modelo computacional}

O objeto de estudo selecionado foi o edifício dos Laboratórios de Engenharia (Figura 1) da Universidade Federal de Viçosa, latitude $20,75^{\circ} \mathrm{S}$ e longitude $42,88^{\circ} \mathrm{O}$, a $649 \mathrm{~m}$ acima do nível do mar, na Zona Bioclimática 3. De clima tropical de altitude com verão chuvoso e temperaturas amenas com brusca variação diária, tem temperaturas mínimas mensais que variam de $10,1^{\circ} \mathrm{C}$ a $18,1{ }^{\circ} \mathrm{C}$; médias mensais entre $15,4{ }^{\circ} \mathrm{C}$ e $22,3{ }^{\circ} \mathrm{C}$, e máximas mensais de $23,5{ }^{\circ} \mathrm{C}$ a $30{ }^{\circ} \mathrm{C}$. Sua umidade relativa mensal varia de $76 \%$ a $84 \%$.

O edifício foi selecionado devido ao fato de sua envoltória ter apresentado nível de eficiência energética " $\mathrm{A}$ " pelo método prescritivo e por ser um edifício naturalmente condicionado. Como Carlo e Lamberts (2008) apontam, as equações de regressão presentes no método prescritivo foram desenvolvidas para edifícios condicionados artificialmente, e não são aceitas para aplicação em edifícios condicionados naturalmente. Como o desempenho de uma envoltória em uma edificação condicionada naturalmente pode ser distinto da mesma envoltória em uma edificação condicionada artificialmente, diferenças entre os níveis de eficiência podem ser encontradas, e o método prescritivo foi utilizado para uma indicação inicial de suas tendências, cuja maior precisão só pode ser obtida pelo método de simulação (CARLO; LAMBERTS, 2010b).
${ }^{3}$ No RTQ-C (INSTITUTO..., 2010), a tabela que relaciona o POC ao EqNumV é a Tabela 6.4, presente no método de simulação para ambientes naturalmente ventilados. 
Tabela 1 - Níveis de eficiência de acordo com o intervalo de equivalente numérico

\begin{tabular}{c|c|c}
\hline EqNum ou PT & Nível de eficiência & Percentual de horas ocupadas em conforto \\
\hline$\geq 4,5$ a 5 & A & POC $\geq 80 \%$ \\
$\geq 3,5 \mathrm{a}<4,5$ & $\mathrm{~B}$ & $70 \% \leq \mathrm{POC}<80 \%$ \\
$\geq 2,5 \mathrm{a}<3,5$ & $\mathrm{C}$ & $60 \% \leq \mathrm{POC}<70 \%$ \\
$\geq 1,5 \mathrm{a}<2,5$ & $\mathrm{D}$ & $50 \% \leq \mathrm{POC}<60 \%$ \\
$<1,5$ & $\mathrm{E}$ & $\mathrm{POC}<50 \%$ \\
\hline
\end{tabular}

Fonte: Instituto Nacional de Metrologia, Normalização e Qualidade Industrial (2010).

Figura 1 - Vista da maquete eletrônica dos Laboratórios de Engenharia - UFV
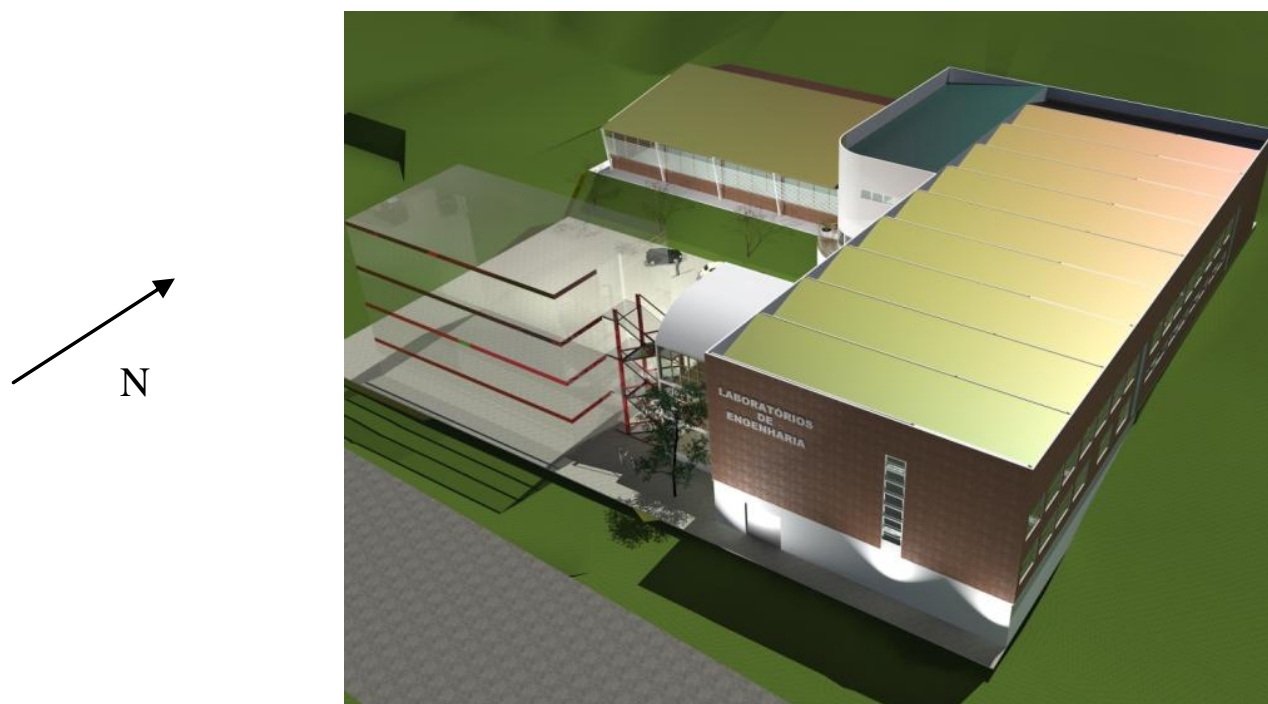

Fonte: Araújo (2010).

$O$ projeto arquitetônico do Edifício dos Laboratórios de Engenharia prevê a construção de aproximadamente $4.800 \mathrm{~m}^{2}$, distribuídos em três pavimentos, nos quais se localizam depósitos, laboratórios ${ }^{4}$ leves e pesados de engenharia, salas de aula e gabinetes de professores. Além disso, o edifício possui ambientes típicos para atender a infraestrutura de departamentos acadêmicos, com secretarias, salas de reunião e um auditório [...]. (ARAÚJO, 2010, p. 90).

Conta ainda com uma ponte rolante e laje de reação, que possibilitarão a realização de experimentos complexos. O edifício Laboratórios de Engenharia está conectado ao edifício do Centro de Ciências Exatas e Tecnológicas (CCE) e apresenta volumetria em "L". A avaliação ocorreu apenas neste novo bloco; portanto, considerou-se que não há o edifício do CCE.

${ }^{4}$ Laboratórios de equipamentos leves e pesados utilizados em engenharia: de instrumentos portáteis a equipamentos de ensaio de compressão ou pontes rolantes para transporte de carga.

\section{Caso-base}

O edifício foi modelado segundo as especificações de projeto (Figura 2). O modelo apresenta 91 zonas, enquanto o projeto do edifício apresenta 83 ambientes. A diferença entre as zonas térmicas e os ambientes refere-se à modelagem de ambientes intermediários, como átrios de cobertura e caixas de escada. Além disso, $71,4 \%$ do edifício se constituem em ambientes de permanência prolongada, e 28,1\%, em ambientes de permanência transitória (Tabela 2).

O modelo de rede de ventilação natural adotado, Airflow Network, realiza trocas de massa e energia entre as zonas térmicas, selecionado com base na análise de Carlo e Lamberts (2010b) e com as especificações de Versage (2009). Ele foi configurado com padrão de abertura das janelas de $20 \%$ a $100 \%$ da área disponível para ventilação a cada vez que a temperatura interna da zona ultrapassa $22^{\circ} \mathrm{C}$, durante o período em que a edificação esteja ocupada. Os coeficientes de descarga utilizados variaram de 0,52 a 0,80 , de acordo com o modelo da janela, e foram de 0,68 para portas. As portas internas permaneceram com $100 \%$ de áreas de abertura de ventilação em $100 \%$ do ano, e os nós externos foram modelados com 
um coeficiente de pressão para cada janela e a cada variação de $10^{\circ}$ de direção do vento sobre a fachada com uso do TNO CP Generator (GUIMARÃES; CARLO, 2012). O padrão de uso de ocupação e a densidade de carga interna (DCI) devido a equipamentos, iluminação e pessoas foram, em média, $41 \mathrm{~W} / \mathrm{m}^{2}, 5 \mathrm{~W} / \mathrm{m}^{2}$ e 12 $\mathrm{m}^{2} /$ pessoa respectivamente (GUIMARÃES; CARLO, 2012).

Para a simulação, foram eliminados os sombreamentos no entorno do edifício, como edificações adjacentes e acidentes geográficos. O autossombreamento devido à forma do edifício e o sombreamento por beirais e platibandas foram mantidos. A inércia térmica da laje de reação de 80 $\mathrm{cm}$ de espessura em concreto armado também foi incluída na modelagem.

Há oito tipos de paredes externas e quatro tipos de cobertura no caso-base, que variam de acordo com sua localização. A Tabela 3 apresenta seus componentes com suas respectivas absortâncias solares das superfícies externas e transmitâncias térmicas.

\section{Definição das Medidas de Conservação de Energia (MCE)}

As medidas de conservação de energia (MCE) foram selecionadas por sua viabilidade de modelagem numérica pelo programa, pela facilidade de avaliação pela simulação em relação ao método prescritivo e pelo tempo disponível para a pesquisa. Elas encontram-se relacionadas na Tabela 4, juntamente com o caso-base. No total, são 16 alternativas de simulação cujas MCE foram integradas ao caso-base.

As alternativas 1 mantiveram as paredes conforme o caso-base, com alterações apenas no fator solar do vidro. As alternativas 6 apresentaram aberturas zenitais presentes no projeto arquitetônico original, que foram eliminadas do caso-base, e também diferenciaram-se entre si pelo fator solar do vidro. As alternativas 7 tiveram todas as superfícies verticais externas uniformizadas com a mesma absortância solar, visto que o caso-base apresenta absortâncias distintas nas diversas paredes.

\section{Figura 2 - Vista do modelo real dos Laboratórios de Engenharia}

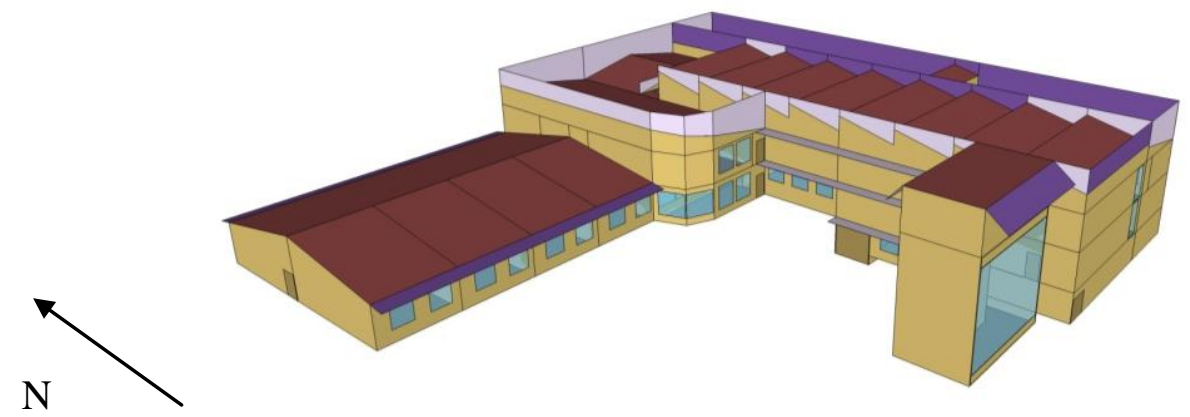

Tabela 2 - Relação de áreas do edifício por pavimento e uso

\begin{tabular}{c|c|c}
\hline Tipos de ambientes & Área & Percentual sobre o total \\
\hline Ambientes de permanência prolongada & $2.928,5 \mathrm{~m}^{2}$ & $71,9 \%$ \\
Ambientes de permanência transitória & $1.141,7 \mathrm{~m}^{2}$ & $28,1 \%$ \\
Área total & $4.070,2 \mathrm{~m}^{2}$ & \\
\hline Espaços internos & Quantidade de zonas & Percentual sobre o total \\
\hline Térreo & 6 & $6,8 \%$ \\
$1^{\mathbf{o}}$ pavimento & 34 & $37,8 \%$ \\
$2^{\mathbf{o}}$ pavimento & 37 & $40,7 \%$ \\
Cobertura & 10 & $10,2 \%$ \\
Circulação vertical & 4 & $4,5 \%$ \\
Total & 91 & $100 \%$ \\
\hline
\end{tabular}

110 Nakamura, N. K.; Maciel, L. F.; Carlo, J. C. 
Tabela 3 - Propriedades da envoltória: absortância solar e transmitância térmica

\begin{tabular}{c|l|c|c}
\hline & \multicolumn{1}{|c|}{ Material } & $\boldsymbol{\alpha}$ & $\mathbf{U}\left(\mathbf{W} / \mathbf{m}^{2} \cdot \mathbf{K}\right)$ \\
\hline \multirow{5}{*}{ Parede } & tijolo & 0,75 & 1,928 \\
& tijolo + reboco & 0,75 & 1,651 \\
& tijolo + argamassa + cerâmica & 0,75 & 1,88 \\
& tijolo + argamassa + madminer & 0,75 & 1,031 \\
& emboço + tijolo & 0,20 & 1,541 \\
& emboço + tijolo + reboco & 0,20 & 1,359 \\
& reboco + tijolo de 6 furos + reboco & 0,20 & 2,087 \\
& emboço + tijolo + argamassa + cerâmica & 0,20 & 1,509 \\
\hline \multirow{5}{*}{ Cobertura } & 0,20 & 0,5 \\
& metálica simples & 0,25 & 0,405 \\
& metálica do tipo sanduíche & 0,25 & 0,319 \\
& metálica dupla + reboco + forro acústico & 0,20 & 2,355 \\
\hline
\end{tabular}

Tabela 4 - Características aplicadas às alternativas ao caso-base que contém as medidas de conservação de energia

\begin{tabular}{|c|c|}
\hline Modelo & Características \\
\hline Caso-base & De acordo com o projeto arquitetônico \\
\hline Alternativa $1 \mathrm{~A}$ & $\begin{array}{l}\text { Planos envidraçados paralelos à fachada com câmara de ar e } \\
\text { superfícies opacas internas. O vidro apresenta fator solar de } 0,83\end{array}$ \\
\hline Alternativa 1B & $\begin{array}{l}\text { Planos envidraçados paralelos à fachada com câmara de ar e } \\
\text { superfícies opacas internas. O vidro apresenta fator solar de } 0,50\end{array}$ \\
\hline Alternativa $1 \mathrm{C}$ & $\begin{array}{l}\text { Planos envidraçados paralelos à fachada com câmara de ar e } \\
\text { superfícies opacas internas. O vidro apresenta fator solar de } 0,20\end{array}$ \\
\hline Alternativa 2A & Brises triangulares horizontais \\
\hline Alternativa 4A & $\begin{array}{l}\text { Brises opacos paralelos à fachada com aletas de } 12,5 \mathrm{~cm} \mathrm{e} \\
\text { distância entre as aletas de } 12,5 \mathrm{~cm}^{*}\end{array}$ \\
\hline Alternativa 4B & $\begin{array}{l}\text { Brises opacos paralelos à fachada com aletas de } 25,0 \mathrm{~cm} \mathrm{e} \\
\text { distância entre as aletas de } 12,5 \mathrm{~cm}^{2}\end{array}$ \\
\hline Alternativa 5A & $\begin{array}{l}\text { Brises translúcidos paralelos à fachada com aletas de } 12,5 \mathrm{~cm} \text { e } \\
\text { distância entre as aletas de } 12,5 \mathrm{~cm}^{2} \text {. Transmitância solar }=50 \%\end{array}$ \\
\hline Alternativa 5B & $\begin{array}{l}\text { Brises translúcidos paralelos à fachada com aletas de } 25,0 \mathrm{~cm} \text { e } \\
\text { distância entre as aletas de } 12,5 \mathrm{~cm}^{2} \text {. Transmitância solar }=50 \%\end{array}$ \\
\hline Alternativa $6 \mathrm{~A}$ & $\begin{array}{l}\text { Aberturas zenitais com área igual a } 1 / 10 \text { da área do ambiente, } 1 \% \\
\text { de PAZ e vidro com fator solar igual a } 0,83\end{array}$ \\
\hline Alternativa 6B & $\begin{array}{l}\text { Aberturas zenitais com área igual a } 1 / 10,1 \% \text { de PAZ e vidro da } \\
\text { área do ambiente e vidro com fator solar igual a } 0,50\end{array}$ \\
\hline Alternativa $6 \mathrm{C}$ & $\begin{array}{l}\text { Aberturas zenitais com área igual a } 1 / 10 \text { da área do ambiente, } 1 \% \\
\text { de PAZ e vidro e vidro com fator solar igual a } 0,20\end{array}$ \\
\hline Alternativa 7A & Absortância das paredes externas $=0,25$ \\
\hline Alternativa 7B & Absortância das paredes extern \\
\hline Alternativa 7C & Absortância das paredes externas $=0,75$ \\
\hline Alternativa $8 \mathrm{~A}$ & Modelo do edifício real sem proteções solares ou beirais \\
\hline
\end{tabular}

Nota: *os elementos paralelos à fachada distam $30,0 \mathrm{~cm}$ da parede externa.

\section{Especificidades em relação ao método de simulação do RTQ-C}

A simulação computacional, realizada no programa EnergyPlus versão 5.0, e o tratamento dos resultados seguiram o RTQ-C (INSTITUTO..., 2010) em quase todos os procedimentos. As condições de conforto foram analisadas de acordo com a ASHRAE Standard 55
(INTERNATIONAL..., 2010), em que as temperaturas operativas foram utilizadas para avaliar uma aceitação de $80 \%$, de acordo com a adaptabilidade do ocupante à temperatura média mensal do ambiente exterior. No entanto, apesar de o RTQ-C exigir o POC dos ambientes apenas das horas ocupadas do edifício (Figura 3a), neste trabalho o conforto foi independente da condição prevista de ocupação, visto que a ocupação real 
pode ser variável e independe dos parâmetros do RTQ-C. Assim, o POC foi considerado como percentual de horas em conforto e, portanto, foi chamado de PHC. O PHC de cada ambiente gerou um equivalente numérico de ventilação do ambiente $\left(\mathrm{EqNumV}_{\mathrm{amb}}\right)$ - indicador numérico que determina o nível de eficiência da envoltória de ambientes condicionados naturalmente - e sua média ponderada gerou o EqNumV do edifício (Equação 3), conforme a Figura 3b. Em seguida, os PHC médios e os níveis de eficiência do casobase foram comparados com os de cada alternativa, e, consequentemente, com o impacto de cada MCE no nível de eficiência da envoltória do edifício. Neste trabalho, um novo método de cálculo foi avaliado: o PHC médio do edifício, obtido a partir da média ponderada dos percentuais de horas ocupadas em conforto de todas as zonas por suas áreas de piso (Equação 4). O PHC foi utilizado na análise de uma opção alternativa de cálculo do EqNumV: o PHC ponderado (Equação 4) gerou o EqNumV do edifício, sem ponderação de equivalentes numéricos dos ambientes, conforme Figura 3c. Após calculado o $\mathrm{PHC}_{\mathrm{ed}}$, o EqNumV $_{\text {ed }}$ foi obtido pela Tabela 1. Portanto, a Figura 3a refere-se ao método do RTQ-C, onde se usa a tabela de conversão em equivalentes numéricos (Tabela 1) e, em seguida, a equação de ponderação (Equação 3). A Figura 3b refere-se ao mesmo método, porém, com o PHC. E a Figura 3c, a um método em que se usa uma equação de ponderação (Equação 4) e, em seguida, a tabela de conversão (Tabela 1). Esses procedimentos são aplicados a todos os modelos a serem simulados.

\section{Níveis de eficiência das envoltórias}

\section{Caso-base}

A envoltória do caso-base apresentou nível de eficiência B, cujo equivalente numérico foi de 4,06 e o PHC médio de $80 \%$. A ocorrência de desconforto e sua localização estão especificadas na Tabela 5, bem como as principais causas bioclimáticas para tais condições.

Verificou-se que o térreo - subsolo parcial apresentou os maiores percentuais de desconforto por frio de todo o edifício, devido ao contato com o solo, que retira grande parte do calor presente nessas zonas por transmissão do piso e das paredes. Vale ressaltar que essas zonas são de permanência transitória, como depósitos e vestiários.

Já no primeiro pavimento, verificou-se que as zonas localizadas a norte apresentaram apenas $5 \%$ de horas em desconforto por frio, com exceção de uma zona térmica de área substancialmente maior que as demais. As zonas localizadas a leste foram as que apresentaram maiores horas em conforto, com média de apenas 5\% de horas do ano em desconforto. As zonas com fachada externa voltada a oeste apresentaram maiores percentuais de horas em desconforto por frio (cerca de 25\%), devido ao já citado contato com o solo e ao autossombreamento de parte das fachadas oeste. Já as zonas com fachada externa voltada ao sul apresentaram os maiores percentuais de desconforto por frio (cerca de $35 \%$ ), por receberem pouca radiação solar direta.

Figura 3 - Diferenças entre os métodos de cálculo do RTQ-C (3a) e o do presente trabalho (3b e 3c)

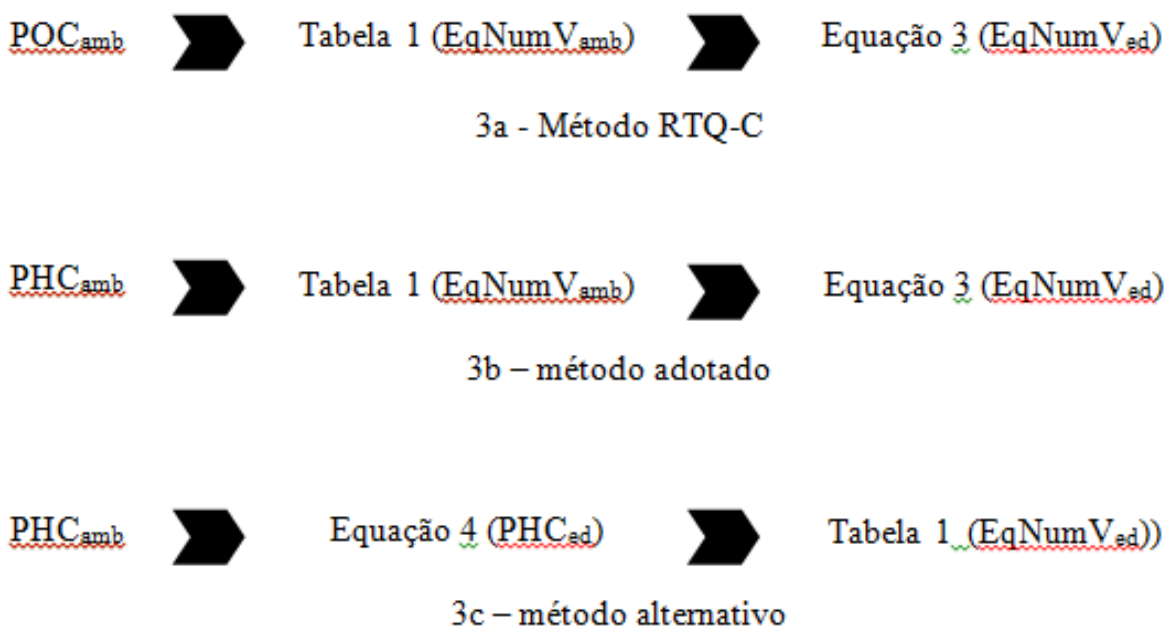

Nota: EqNumV $_{\text {ed }}=\left(\Sigma E_{\text {EqNumV }}\right.$ amb.$\left.A_{a m b}\right) / A_{\text {ed }}(E q .3)$ e PHCed $=\left(\Sigma P H C . A_{a m b}\right) A_{\text {ed }}(E q .4)$. Onde: EqNumV é o equivalente numérico de ventilação para envoltórias condicionadas naturalmente; PHC é o percentual de horas em conforto no ano completo; e A é a área útil de piso. 
Tabela 5 - Condições de conforto no caso-base*

\begin{tabular}{|c|c|c|c|c|c|c|}
\hline \multirow{2}{*}{$\begin{array}{l}\text { Percentual médio de } \\
\text { conforto ou } \\
\text { desconforto no ano }\end{array}$} & \multicolumn{4}{|c|}{ Percentual de área } & \multirow{2}{*}{$\begin{array}{c}\text { Orientação } \\
\text { solar }\end{array}$} & \multirow{2}{*}{ Causas mais relevantes } \\
\hline & Edifício & Térreo & $1^{\circ}$ pav & $2^{\circ}$ pav & & \\
\hline Conforto & $29 \%$ & $0 \%$ & $42 \%$ & $57 \%$ & Norte e leste & $\begin{array}{c}\text { Contato com a cobertura e } \\
\text { incidência de radiação } \\
\text { solar }\end{array}$ \\
\hline $\begin{array}{c}10 \% \text { a } 20 \% \text { de } \\
\text { desconforto por frio }\end{array}$ & $27 \%$ & $0 \%$ & $91 \%$ & $7 \%$ & Norte e leste & $\begin{array}{l}\text { Contato com o solo, mas } \\
\text { com incidência de radiação } \\
\text { solar }\end{array}$ \\
\hline $\begin{array}{l}20 \% \text { a } 30 \% \text { de } \\
\text { desconforto por frio }\end{array}$ & $7 \%$ & $0 \%$ & $96 \%$ & $0 \%$ & $\begin{array}{l}\text { Sul e zonas } \\
\text { internas }\end{array}$ & $\begin{array}{l}\text { Contato com o solo e baixa } \\
\text { incidência de radiação } \\
\text { solar }\end{array}$ \\
\hline $\begin{array}{l}30 \% \text { a } 40 \% \text { de } \\
\text { desconforto por frio }\end{array}$ & $20 \%$ & $11 \%$ & $72 \%$ & $18 \%$ & $\begin{array}{l}\text { Sul, oeste e } \\
\text { zonas } \\
\text { internas }\end{array}$ & $\begin{array}{l}\text { Contato com o solo e baixa } \\
\text { incidência de radiação } \\
\text { solar }\end{array}$ \\
\hline $\begin{array}{l}\geq 40 \% \text { de desconforto } \\
\text { por frio }\end{array}$ & $17 \%$ & $67 \%$ & $11 \%$ & $22 \%$ & $\begin{array}{l}\text { Sul e zonas } \\
\text { em subsolo } \\
\text { parcial }\end{array}$ & $\begin{array}{c}\text { Contato com o solo e } \\
\text { ausência de radiação solar }\end{array}$ \\
\hline
\end{tabular}

Nota: *os percentuais de cada linha não excluem os percentuais da linha seguinte, visto que a mesma área do edifício pode apresentar conforto em um horário e desconforto em outro horário.

As zonas do segundo pavimento apresentaram-se, em sua maioria, em conforto. Entre os motivos, pode-se citar: a pequena área dos ambientes; a falta de contato destes ambientes com o solo; e o contato com a cobertura. Desse modo, os ambientes do segundo pavimento foram mais aquecidos que os do primeiro.

\section{Comparação entre o caso-base e as alternativas}

A Figura 4 mostra o equivalente numérico da envoltória no eixo das coordenadas e o PHC médio, como rótulo, de todas as alternativas, comparando-as ao caso-base. Vale lembrar que o EqNumV foi calculado conforme o método de ponderação do RTQ-C (INSTITUTO..., 2010), cujos EqNumV dos ambientes são ponderados para se encontrar o EqNumV do edifício. O PHC médio é utilizado apenas como um parâmetro complementar de análise.

Pode-se constatar que apenas a alternativa do plano de vidro paralelo à fachada (1A) apresentou nível de eficiência $\mathrm{A}$, equivalente numérico de 4,57 e PHC médio de $84 \%$. Todas as outras apresentaram o nível $\mathrm{B}$, inclusive o caso-base, cujo equivalente numérico foi de 4,06 e cujo PHC médio foi $79 \%$.

Pode-se constatar também que, das 16 alternativas propostas, 10 apresentaram PHC e, portanto, níveis de eficiência maiores que o do caso-base, e 6 apresentaram PHC menores.

A alternativa 1A apresentou o maior equivalente numérico, e a 4B, o menor. A primeira alternativa representa o modelo com planos envidraçados paralelos à fachada com câmara de ar e superfícies opacas internas (alvenaria), cujo fator solar do vidro foi o maior simulado, de 0,83 . Já a segunda representa brises horizontais opacos e paralelos à fachada com aletas de $25,0 \mathrm{~cm}$ e distanciadas em $12,5 \mathrm{~cm}$ entre si, que abrange o maior sombreamento simulado. Portanto, para condições onde as horas de desconforto por frio são maiores que as de desconforto por calor, as medidas de aquecimento foram as mais eficientes. A análise, no entanto, pode ser inversa para condições de desconforto por calor. A seguir, tais resultados são analisados ao comparar-se individualmente cada alternativa com o caso-base.

Pode-se constatar que apenas a alternativa do plano de vidro paralelo à fachada (1A) apresentou nível de eficiência $\mathrm{A}$, equivalente numérico de 4,57 e PHC médio de $84 \%$. Todas as outras apresentaram o nível B, inclusive o caso-base, cujo equivalente numérico foi de 4,06 e cujo PHC médio foi $79 \%$.

Pode-se constatar também que, das 16 alternativas propostas, 10 apresentaram $\mathrm{PHC}$ e, portanto, níveis de eficiência maiores que o do caso-base, e 6 apresentaram PHC menores. 
Figura 4 - Nível de eficiência e o PHC das alternativas e do caso-base - a linha tracejada está alinhada com o EqNumV do caso-base, de 4,06, nível de eficiência $B$

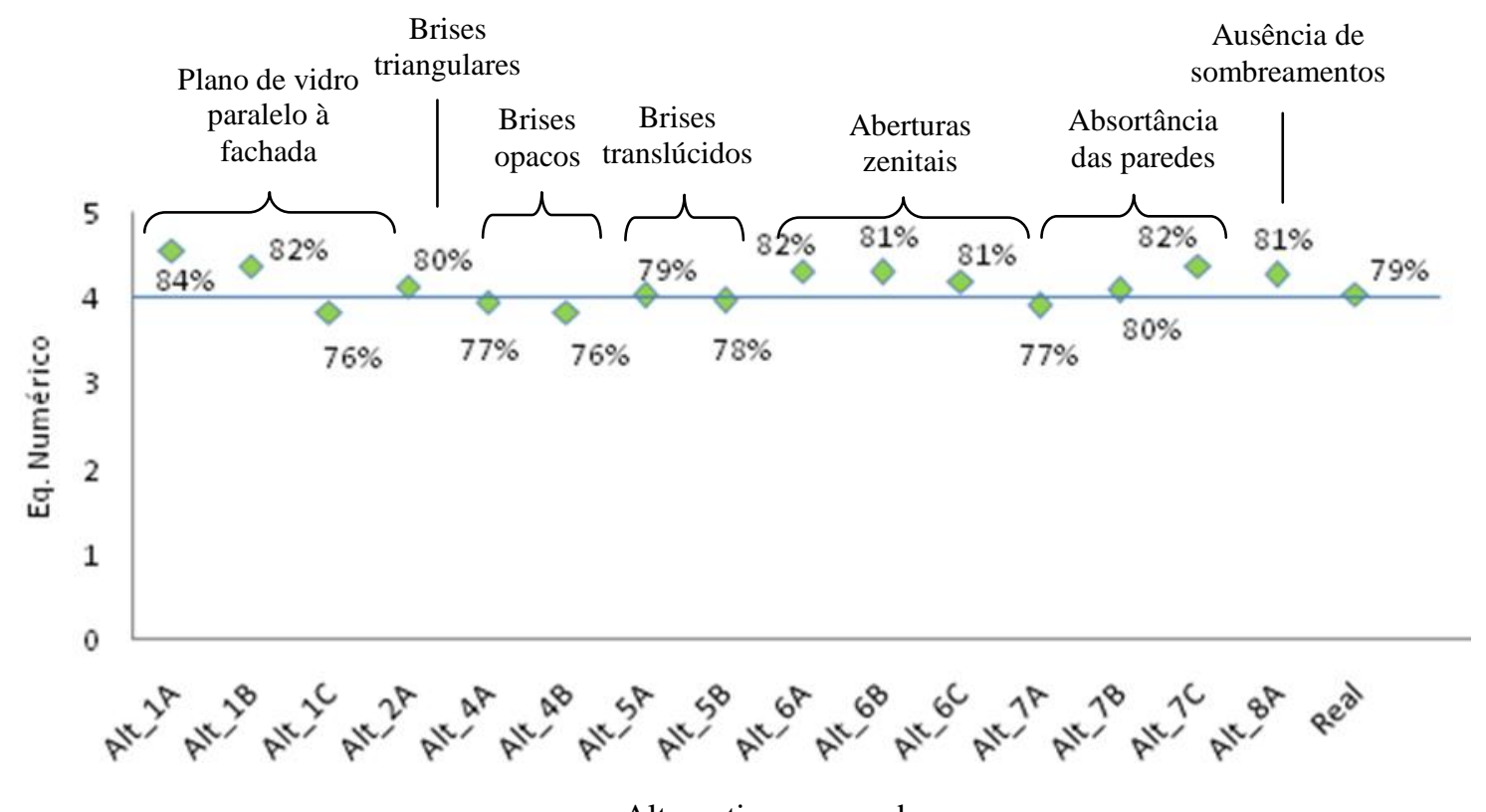

Alternativas e caso-base

A alternativa $1 \mathrm{~A}$ apresentou o maior equivalente numérico, e a 4B, o menor. A primeira alternativa representa o modelo com planos envidraçados paralelos à fachada com câmara de ar e superfícies opacas internas (alvenaria), cujo fator solar do vidro foi o maior simulado, de 0,83 . Já a segunda representa brises horizontais opacos e paralelos à fachada com aletas de $25,0 \mathrm{~cm}$ e distanciadas em $12,5 \mathrm{~cm}$ entre si, que abrange o maior sombreamento simulado. Portanto, para condições onde as horas de desconforto por frio são maiores que as de desconforto por calor, as medidas de aquecimento foram as mais eficientes. A análise, no entanto, pode ser inversa para condições de desconforto por calor. A seguir, tais resultados são analisados ao comparar-se individualmente cada alternativa com o caso-base.

De acordo com a Figura 4, pode-se perceber que as alternativas que possuem um plano de vidro paralelo à fachada apresentaram, em sua maioria, equivalentes numéricos mais elevados que o casobase (4,06), pois este último apresenta, predominantemente, horas de desconforto por frio. A diferença entre as três alternativas está no fator solar do vidro de 0,83, 0,50 e 0,20, EqNum de 4,57, 4,39 e 3,84 respectivamente. Desse modo, o plano de vidro paralelo à fachada, com FS elevado, que permite a transmissão da radiação solar absorvida pelo vidro ao ambiente, eleva a temperatura interna e ameniza o desconforto por frio. Essa medida chegou a gerar zonas com desconforto por calor.
Os resultados da alternativa $2 \mathrm{~A}$, de brises horizontais triangulares, e do caso-base foram semelhantes, com algumas poucas zonas com menor número de horas de conforto na alternativa. Este fato se deve à presença de proteções solares horizontais em ambos os casos, porém com formatos diferentes. $\mathrm{O}$ caso-base apresenta beirais que sombreiam algumas aberturas, enquanto a alternativa $2 \mathrm{~A}$ apresenta os brises em formato triangular. Desse modo, conclui-se que, para este caso, o formato combinado com as dimensões dos brises não exerceu grande influência no resultado final da edificação, já que a intensidade da radiação solar recebida pelos ambientes foi semelhante. No entanto, deve-se confirmar esse resultado com outras dimensões de brises triangulares, seja por máscara de sombra sobre a carta solar, seja por simulação com brises horizontais retangulares.

As alternativas 4A e 4B de brises horizontais paralelos à fachada apresentaram $\mathrm{PHC}$ menor do que o caso-base. Esses brises, por serem opacos, diminuíram a entrada de radiação solar no ambiente, aumentando ainda mais as horas de desconforto por frio. Além disso, a alternativa de maiores aletas $(25,0 \mathrm{~cm})$ apresentou o menor equivalente numérico entre todas $(3,83)$.

As alternativas 5A e 5B (brises horizontais translúcidos) apresentaram menores índices de conforto que o caso-base, pois, apesar de permitirem a passagem de $50 \%$ da energia térmica por radiação, ainda impediram que parte desta fosse transmitida ao ambiente interno de modo a 
aquecê-lo, o que gerou horas de conforto ligeiramente menores no caso-base.

As alternativas 6A, 6B e 6C obtiveram maior nível de eficiência $(82 \%, 81 \%$ e $81 \%$ respectivamente) em relação ao caso-base, obviamente devido à radiação pelas aberturas zenitais, que propiciaram o aumento da temperatura. Convém atentar ao fato de que apenas três zonas tinham aberturas zenitais, o que representa um percentual de $12,37 \%$ da área total do edifício. A abertura zenital possui área equivalente a $10 \%$ da área de cada uma das zonas. Porém, elas influenciaram mais 13 zonas adjacentes devido a trocas de calor por ventilação entre zonas ou por transmissão pelas paredes, e também foram consideradas na análise, o que representou um total de $23,75 \%$ da área do edifício que foi impactada pelas aberturas zenitais. Ou seja, aberturas em zonas que ocupam $12,37 \%$ da área total do edifício impactaram o nível de conforto de $23,75 \%$ da área do edifício. Cabe ressaltar que todas essas zonas estão no $1^{\circ}$ pavimento, sem ter havido alterações nos demais pavimentos.

De acordo com os resultados das alternativas 7A, 7B e 7C, onde foram aplicadas diferentes absortâncias solares às superfícies das paredes externas, o percentual de conforto dos ambientes foi proporcional ao valor da absortância, ou seja, quanto maior a absortância, maior o PHC médio, como esperado.

A alternativa 8 apresentou PHC médio ligeiramente mais elevado que o do caso-base, devido à ausência de proteções solares na alternativa. Essa ausência possibilitou a entrada de maior radiação solar no edifício e o consequente aumento da temperatura interna dos ambientes, tornando-os mais confortáveis. No entanto, essa medida não foi suficiente para elevar o nível de eficiência de B para A, com elevação apenas do PHC médio de $79 \%$ no caso-base para $81 \%$ na alternativa.

\section{Considerações sobre os resultados e o RTQ-C}

\section{Absortância solar}

No método prescritivo, o RTQ-C define que, para as zonas bioclimáticas de 2 a 8 , é obrigatória a utilização de materiais de revestimento externo de paredes com absortância solar baixa $(\alpha<0,50)$, para alcançar os níveis de eficiência A e B (INSTITUTO..., 2010). A cidade de Viçosa encontra-se na zona bioclimática 3. Porém, a alternativa $7 \mathrm{C}$, que teve a absortância da superfície externa da parede de 0,75 , foi a que apresentou o melhor percentual de horas ocupadas em conforto $(82 \%)$ entre todas as alternativas, devido à necessidade de aquecimento no inverno. Embora todas tenham alcançado o nível $\mathrm{B}$ de eficiência, percebe-se que há casos em que a elevada absortância é a indicada para a zona bioclimática 3.

Ainda, a Tabela 6 mostra a comparação dos resultados das alternativas dos grupos 1 e 7 simuladas com a avaliação dos pré-requisitos de absortância pelo método prescritivo. Vale lembrar que, para aplicar o método prescritivo no grupo de alternativas 1, deve-se utilizar a Equação 2. A Tabela 6 contém as variáveis usadas no cálculo da Equação 2, e seu resultado, os equivalentes numéricos alcançados pelo método de simulação e pela avaliação dos pré-requisitos, e ainda o PHC médio de cada alternativa.

As alternativas 1A e 7C mostraram como a estratégia de aquecimento pode ser mais relevante que a de resfriamento para alguns edifícios naturalmente condicionados e localizados na zona bioclimática 3: embora $1 \mathrm{~A}$ tenha resultado em nível A pelo método de simulação e 7C, nível B, o método prescritivo permitiria apenas o nível de eficiência C. Nas demais alternativas, o método prescritivo permite que se alcance nível $\mathrm{A}$, enquanto a simulação alcança somente nível B, e, portanto, concordam com os conceitos aplicados no método prescritivo. Acredita-se que essas alternativas ainda possam obter nível A por simulação com a inserção de poucas medidas de conservação de energia (MCE).

Portanto, a análise mostra que as condições de conforto em edifícios naturalmente condicionados na zona bioclimática 3 são variáveis e que o método prescritivo apresenta requisitos gerais, porém não podem ser considerados definitivos na descrição do nível de eficiência.

Duas observações podem ser destacadas. A primeira é a confirmação da importância da simulação para comprovar a qualidade energética de casos específicos, principalmente envolvendo o condicionamento natural, que não podem ser previstas em regulamentos pela própria limitação de situações que eles podem abranger ou prever. A segunda é o destaque à necessidade de mensuração dessa variável para outros tipos de edifícios naturalmente condicionados, em especial para outras localidades pertencentes à zona bioclimática 3, a fim de avaliar a relevância do limite de absortância solar de 0,50 nos pré-requisitos. Localidades como Belo Horizonte, São Paulo, Florianópolis e Porto Alegre podem ser avaliadas. 
Tabela 6 - Absortâncias solares ponderadas das alternativas, seus níveis de eficiência e sua aplicação segundo o método prescritivo

\begin{tabular}{|c|c|c|c|c|c|c|}
\hline & \multicolumn{3}{|c|}{$\begin{array}{l}\text { Planos envidraçados paralelos à fachada com } \\
\text { câmara de ar e superfícies opacas internas }\end{array}$} & \multicolumn{3}{|c|}{ Paredes opacas } \\
\hline & $\begin{array}{c}\mathbf{1 A} \\
(\mathbf{F S}=\mathbf{0 , 8 3})\end{array}$ & $1 \mathrm{~B}(\mathrm{FS}=\mathbf{0 , 5 0 )}$ & $1 \mathrm{C}(\mathrm{FS}=\mathbf{0 , 2 0})$ & 7A & 7B & $7 \mathrm{C}$ \\
\hline$\alpha_{\text {parede }}($ ponderado $)$ & 0,75 & 0,75 & 0,75 & 0,25 & 0,50 & 0,75 \\
\hline$\alpha_{\mathrm{vidro}} *$ & 0,15 & 0,75 & 0,80 & - & - & - \\
\hline$\tau_{\text {vidro }}$ & 0,778 & 0,337 & 0,078 & - & - & - \\
\hline $\mathrm{FS}_{\text {vidro }}$ & 0,83 & 0,50 & 0,20 & - & - & - \\
\hline$\alpha_{\text {total }}($ Equação 2) & 0,62 & 0,38 & 0,15 & - & - & - \\
\hline $\begin{array}{l}\text { EqNumEnv } v_{\text {máx }} \text { método } \\
\text { prescritivo }\end{array}$ & $\begin{array}{c}3 \\
(\mathrm{C})\end{array}$ & $\begin{array}{c}5 \\
(\mathrm{~A})\end{array}$ & $\begin{array}{c}5 \\
(\mathrm{~A})\end{array}$ & $\begin{array}{c}5 \\
(\mathrm{~A})\end{array}$ & $\begin{array}{c}5 \\
(\mathrm{~A})\end{array}$ & $\begin{array}{c}3 \\
(\mathrm{C})\end{array}$ \\
\hline EqNumV simulado & $\begin{array}{l}4,57 \\
(\mathrm{~A})\end{array}$ & $\begin{array}{c}4,39 \\
(\mathrm{~B})\end{array}$ & $\begin{array}{c}3,84 \\
(\mathrm{~B})\end{array}$ & $\begin{array}{l}4,27 \\
(\mathrm{~B})\end{array}$ & $\begin{array}{l}4,27 \\
(\mathrm{~B})\end{array}$ & $\begin{array}{c}4,38 \\
\text { (B) }\end{array}$ \\
\hline $\mathrm{PHC}_{\text {méd }}$ simulado & $84 \%$ & $82 \%$ & $76 \%$ & $77 \%$ & $80 \%$ & $82 \%$ \\
\hline
\end{tabular}

Nota: *valores de referência existentes na biblioteca do EnergyPlus.

\section{Aberturas zenitais: o PAZ no RTQ-C}

No método prescritivo, o RTQ-C (INSTITUTO..., 2010) define como pré-requisito para o nível de eficiência A e B que, para o PAZ de $0 \%$ a $2 \%$, o fator solar do vidro deva ser menor que 0,87 (INSTITUTO..., 2010). Nas alternativas 6 (aberturas zenitais), o valor do percentual de abertura zenital (PAZ) do edifício foi de $1 \%$.

A Tabela 7 mostra o impacto de $1 \%$ de PAZ sobre o edifício condicionado naturalmente. Vê-se que, realmente, o impacto do fator solar sobre esse percentual de abertura não é relevante para os percentuais de horas em conforto - destaca-se que as condições de conforto devido à incidência da radiação solar no ambiente não foram avaliadas separadamente -, confirmando as recomendações térmicas referentes ao fator solar ${ }^{5}$ no método prescritivo. No entanto, sua influência no conforto das zonas em que as aberturas zenitais se localizam é relevante, chegando a 5\% das horas (alternativa $6 \mathrm{~A}$ e caso-base), e abrange até $23,12 \%$ da área do edifício para o fator solar de 0,83 .

\section{Equivalente Numérico x PHC}

O RTQ-C (INSTITUTO..., 2010) define que, para a obtenção do nível de eficiência energética de uma edificação, é necessário fazer uma média ponderada dos equivalentes numéricos de todos os ambientes. Porém, caso seja realizada uma média ponderada dos percentuais de horas em conforto de todos os ambientes - independentemente de utilizar horas ocupadas ou não - há diferenças nos resultados. Deve-se observar que um mesmo

\footnotetext{
${ }^{5} \mathrm{O}$ fator solar pode ainda variar por outras condicionantes, como espessura do material translúcido e tipo de material, de acordo com normas de segurança.
}

equivalente numérico abrange um grande intervalo de PHC (0\% a 9\%), e aqueles ambientes que apresentam $71 \%$ de horas em conforto apresentam o mesmo EqNumV daqueles que apresentam 79\%. A Tabela 8 mostra uma comparação dos resultados obtidos com os dois métodos de cálculo.

Assim, verifica-se que, caso o PHC de cada ambiente fosse ponderado pela área para alcançar o nível de eficiência final da edificação, pelo menos 7 alternativas (em negrito) das 16 propostas teriam o nível de eficiência de suas envoltórias alterado de B para A. Ainda, esses resultados foram calculados com um PHC de duas casas decimais. Caso houvesse o arredondamento desses percentuais para números inteiros, as alternativas $2 \mathrm{~A}$ e $7 \mathrm{~B}$ e, inclusive, o caso-base teriam envoltórias com nível A de eficiência.

\section{Conclusão}

Este artigo mostrou a quantificação do nível de eficiência da envoltória de um edifício universitário condicionado naturalmente e localizado na ZB3 com a aplicação de medidas de conservação de energia (MCE), usando um método de simulação baseado no RTQ-C (INSTITUTO..., 2010). Uma alteração em relação ao método original foi a avaliação de $100 \%$ das horas em conforto no ano para verificar o desempenho completo do edifício. Deve-se destacar ainda que a adoção dos índices de conforto da Standard 55 é recomendada pelo RTQ-C, mas apresenta limitações para um edifício com atividade principal de pesquisa e com as estratégias de condicionamento natural adotadas. Pesquisas sobre as condições que proporcionam conforto térmico em usuários de edifícios com uso tão próprio são ainda desejadas. 
Tabela 7 - PHC médio das zonas das alternativas 6

\begin{tabular}{l|c|c|c|c|c}
\hline & A $(\%)$ & Caso-base & $\begin{array}{c}\text { Alternativa 6A } \\
(\mathbf{F S}=\mathbf{0 , 8 3})\end{array}$ & $\begin{array}{c}\text { Alternativa 6B } \\
(\mathbf{F S = 0 , 5 0 )}\end{array}$ & $\begin{array}{c}\text { Alternativa 6C } \\
(\mathbf{F S = 0 , 2 0})\end{array}$ \\
\hline $\begin{array}{l}\text { Zonas com abertura } \\
\text { zenital }\end{array}$ & 12,37 & $72,29 \%$ & $77,15 \%$ & $75,91 \%$ & $73,26 \%$ \\
\hline Zonas adjacentes & 10,75 & $68,44 \%$ & $72,21 \%$ & $70,96 \%$ & $69,56 \%$ \\
\hline $\begin{array}{l}\text { Zonas com abertura } \\
\text { zenital + adjacentes }\end{array}$ & 23,12 & $70,50 \%$ & $74,85 \%$ & $73,61 \%$ & $71,54 \%$ \\
\hline Edifício completo & 100,00 & $79,29 \%$ & $81,94 \%$ & $81,49 \%$ & $80,87 \%$ \\
\hline
\end{tabular}

Tabela 8 - Níveis de eficiência calculados segundo o RTQ-C, pela média ponderada dos equivalentes numéricos, e segundo método alternativo, pela média ponderada dos PHC de cada ambiente

\begin{tabular}{|c|c|c|c|c|}
\hline Alternativa & $\begin{array}{c}\text { EqNumV pelo } \\
\text { método do RTQ-C }\end{array}$ & $\begin{array}{c}\text { Nível de eficiência } \\
\text { devido à ponderação } \\
\text { do EqNumV }\end{array}$ & $\begin{array}{l}\text { PHC médio } \\
\text { ponderado }\end{array}$ & $\begin{array}{c}\text { Nível de eficiência } \\
\text { devido à } \\
\text { ponderação do PHC }\end{array}$ \\
\hline $1 \mathrm{~A}$ & 4,57 & $\mathrm{~A}$ & $83,82 \%$ & $\mathrm{~A}$ \\
\hline $1 B$ & 4,39 & $B$ & $81,80 \%$ & $A$ \\
\hline $1 \mathrm{C}$ & 3,84 & $\mathrm{~B}$ & $75,88 \%$ & $\mathrm{~B}$ \\
\hline $2 \mathrm{~A}$ & 4,15 & B & $79,63 \%$ & $\mathrm{~B}$ \\
\hline $4 \mathrm{~A}$ & 3,95 & $\mathrm{~B}$ & $77,35 \%$ & $\mathrm{~B}$ \\
\hline $4 B$ & 3,83 & $\mathrm{~B}$ & $75,72 \%$ & $\mathrm{~B}$ \\
\hline $5 \mathrm{~A}$ & 4,03 & B & $78,94 \%$ & B \\
\hline $5 B$ & 3,98 & $\mathrm{~B}$ & $78,07 \%$ & $\mathrm{~B}$ \\
\hline $6 A$ & 4,32 & $B$ & $81,94 \%$ & $A$ \\
\hline $6 B$ & 4,31 & $B$ & $81,49 \%$ & $A$ \\
\hline $6 C$ & 4,19 & $\boldsymbol{B}$ & $80,87 \%$ & $A$ \\
\hline $7 \mathrm{~A}$ & 3,91 & B & $77,10 \%$ & $\mathrm{~B}$ \\
\hline $7 \mathrm{~B}$ & 4,09 & $\mathrm{~B}$ & $79,74 \%$ & $\mathrm{~B}$ \\
\hline $7 C$ & 4,38 & $B$ & $82,33 \%$ & $A$ \\
\hline $8 A$ & 4,27 & $B$ & $80,93 \%$ & $A$ \\
\hline $8 B$ & 4,27 & $B$ & $80,94 \%$ & $A$ \\
\hline Caso-base & 4,06 & B & $79,97 \%$ & B \\
\hline
\end{tabular}

Constatou-se que o nível de eficiência da envoltória do caso-base foi $\mathrm{B}$, devido ao desconforto por frio. As MCE simuladas foram:

(a) planos de vidro paralelos à fachada à frente de superfícies opacas;

(b) brises triangulares;

(c) brises horizontais paralelos opacos e translúcidos;

(d) aberturas zenitais com 1\% de PAZ; e

(e) absortância solar da superfície externa das paredes.

As alternativas onde foram inseridos planos de vidro paralelos à fachada foram as que apresentaram o melhor nível de eficiência, devido ao aumento da transmissão de calor para o interior do ambiente. Vale destacar que a alternativa que possuía o maior fator solar $(0,83)$, alcançou nível de eficiência A. Os brises paralelos opacos apresentaram os piores níveis de eficiência energética, devido ao sombreamento nas paredes externas. Além disso, quanto maior o tamanho das aletas, maior o número de horas de desconforto por frio no ambiente interno.

Das medidas de conservação de energia verificadas, as de maior impacto foram as absortâncias das paredes externas, mesmo em uma edificação de formato mais próximo do podium (horizontal) do que da torre (vertical). Ao comparar os resultados da simulação com os prérequisitos de absortâncias solares do método prescritivo, foram encontradas limitações no segundo, e as principais recomendações levantam a importância em simular edifícios naturalmente condicionados, em especial localizados nas zonas bioclimáticas onde as condições de desconforto por frio podem ser mais relevantes que as de desconforto por calor.

Embora os níveis de eficiência das alternativas com PAZ de $1 \%$ e fatores solares diferenciados não se tenham modificado, observou-se um impacto relevante no percentual de horas em 
conforto nas zonas que contêm as aberturas (12,37\% de área do edifício) e também em suas zonas adjacentes $(10,95 \%$ de área do edifício).

Por fim, as considerações no cálculo dos níveis de eficiência segundo o método de simulação do RTQ-C também se mostraram relevantes. O cálculo de médias ponderadas por $\mathrm{PHC}$ ou por equivalentes numéricos (EqNumV) impactam o nível de eficiência da edificação de maneira diferente. $\mathrm{O}$ atual método de cálculo do RTQ-C (INSTITUTO..., 2010) implica menor precisão do nível de eficiência de uma edificação naturalmente ventilada.

Tais avaliações foram realizadas com o fim de quantificar o impacto de medidas para a envoltória, que foram inseridas conceitualmente no RTQ-C (INSTITUTO..., 2010), e podem subsidiar a previsão de casos semelhantes na mesma zona bioclimática. No entanto, deve-se alertar para as especificidades do edifício, como condicionamento natural, grande contato com o solo e formato de podium, além das especificidades adotadas no método, como o uso do PHC no lugar do POC e as condições limitantes da ASHRAE Standard 55 (AMERICAN...2010).

\section{Referências}

AMERICAN SOCIETY OF HEATING, REFRIGERATING AND AIR CONDITIONING ENGINEERS. Standard 140: standard method of test for the evaluation of building energy analysis computer programs. Atlanta, 2004.

\section{AMERICAN SOCIETY OF HEATING, REFRIGERATING AND AIR CONDITIONING ENGINEERS. Standard 55. 2010: thermal environmental conditions for human occupancy. Atlanta, 2010.}

ARAÚJO, A. Proposta Metodológica Para o Projeto de Sistemas de Fechamento em Alvenaria Para Edifícios Institucionais em Estrutura de Aço. 114 f. Voçosa, 2010. Dissertação (Mestrado em Engenharia Civil) Programa de Pós-Graduação em Engenharia Civil, Universidade Federal de Viçosa, Viçosa, 2010.

CARLO, J. C.; LAMBERTS, R. Development of Envelope Efficiency Labels For Commercial Buildings: effect of different variables on electricity consumption. Energy and Buildings, Oxford, v. 40, p. 2002-2008, 2008.
CARLO, J. C.; LAMBERTS, R. Parâmetros e Métodos Adotados no Regulamento de Etiquetagem da Eficiência Energética de Edifícios: parte 1: método prescritivo. Revista Ambiente Construído, Porto Alegre, v. 10, n. 2, p. 7-26, abr./jun. abr./jun. 2010a.

CARLO, J. C.; LAMBERTS, R. Parâmetros e Métodos Adotados no Regulamento de Etiquetagem da Eficiência Energética de Edifícios: parte 2: método de simulação. Revista Ambiente Construído, Porto Alegre, v. 10, n. 2, p. 7-26, abr./jun. 2010b.

CASALS, X. G. Analysis of building energy regulations and certification in Europe: their role, limitations and differences. Energy and Buildings, Oxford, v. 38, p. 381-392, 2006.

COMITÉ EUROPÉEN DE NORMALISATION. EN 15251: indoor environmental input parameters for design and assessment of energy performance of buildings addressing indoor air quality, thermal environment, lighting and acoustics. London, 2007.

CRAWLEY, D. B. et al. Contrasting the Capabilities of Building Energy Performance Simulation Programs. Building and Environment, Oxford, v. 43, p. 661-673, 2008.

DIAZ, C. J.; CZAJKOWSKI, J. D.; CARROCCI, L. R. Uso Eficiente de la Energia Electrica en Edifícios Públicos: el caso del Bloque I de la FEGUNESP. In: Encontro Nacional de Tecnologia do Ambiente Construído, 12., Fortaleza, 2008. Anais... Fortaleza: ANTAC, 2008.

FOSSATI, M.; LAMBERTS, R. Eficiência Energética da Envoltória de Edifícios de Escritórios de Florianópolis: discussões sobre a aplicação do método prescritivo do RTQ-C. Ambiente Construído, Porto Alegre, v. 10, n. 2, p. 59-69, abr./jun. 2010.

GU, L. Airflow Network Modeling in EnergyPlus. In: IBPSA BUILDING SIMULATION CONFERENCE AND EXHIBITION, Beijing, 2007. Proceedings... Beijing: IBPSA, 2007.

GUIMARÃES, I. B. B.; CARLO, J. C. Modelling Issues for the Energy Simulation of a Naturally Ventilated Building According to the Brazilian Labelling Program. In: INTERNATIONAL PASSIVE LOW ENERGY ARCHITECTURE CONFERENCE, 28., Lima, 2012. Proceedings... Lima: PLEA, 2012. 
HERNANDEZ, P.; BURKE, K.; LEWIS, J. O. Development of Energy Performance Benchmarks and Building Energy Ratings for Non-Domestic Buildings: an example for irish primary schools. Energy and Buildings, Oxford, v. 40, p. 249-254, 2008.

\section{INTERNATIONAL ORGANIZATION FOR} STANDARDIZATION. ISO 7730: ergonomics of the thermal environment : analytical determination and interpretation of thermal comfort using calculation of the PMV and PPD indices and local thermal comfort criteria. Geneve, 2005.

INSTITUTO NACIONAL DE METROLOGIA, NORMALIZAÇÃO E QUALIDADE INDUSTRIAL. Portaria 372, de 17 de setembro de 2010, requisitos técnicos da qualidade para o nível de eficiência energética de edifícios comerciais, de serviços e públicos. Rio de Janeiro, 2010. Disponível em:

<http://www.inmetro.gov.br/legislacao/rtac/pdf/RT AC00 1599. pdf>. Acesso em: 05 ago. 2013.

LEE, S. E.; RAJAGOPALAN, P. Building energy efficiency labeling programme in Singapore. Energy Policy, Oxford, v. 36, p. 3982-3992, 2008.

PEDRINI, A. et al. Análise Comparativa da Eficiência Energética de Envoltórias Segundo o Regulamento de Etiquetagem de Edifícios. In: ENCONTRO NACIONAL DE TECNOLOGIA DO AMBIENTE CONSTRUÍDO, 13., Canela, 2010. Anais... Canela: ANTAC, ENTAC, 2010.

POLLOCK, M. et al. Building Simulation as an Assisting Tool in Designing an Energy Efficient Building: a case study. In: BUILDING
SIMULATION, Glasgow, 2009, Proceedings... Glasgow: IBPSA, 2009.

SANTOS, I. G.; SOUZA, R. V. G. Proteções Solares no Regulamento Brasileiro de Eficiência Energética de Edifícios Comerciais, de Serviços e Públicos. Ambiente Construído, Porto Alegre, v. 12, n. 1, p. 277-241, jan./mar. 2012.

STANKEVICIUS, V.; KARBAUSKAITE, J.; MONSTVILAS, E. The Development of Reference Values For Energy Certification of Buildings in Lithuania. Energy and Buildings, Oxford, v. 39, p. 284-288, 2007.

VENÂNCIO, R.; PEDRINI, A. Influência de Decisões Arquitetônicas na Eficiência Energética de Edificações do Campus/UFRN. In: ENCONTRO NACIONAL DE TECNOLOGIA DO AMBIENTE CONSTRUÍDO, 12., Fortaleza, 2008. Anais... Fortaleza: ANTAC, 2008.

VERSAGE, R. de S. Ventilação Natural e Desempenho Térmico de Edifícios Verticais Multifamiliares em Campo Grande, MS. Florianópolis, 2009. Dissertação (Mestrado em Engenharia Civil) - Programa de Pós-Graduação em Arquitetura e Urbanismo, Universidade Federal de Santa Catarina, Florianópolis, 2009.

\section{Agradecimentos}

Os autores agradecem a colaboração de Ítalo Guimarães no desenvolvimento do trabalho e das instituições financiadoras Fapemig e Procel Edifica/Eletrobrás.

\section{Natália Kokumai Nakamura}

Arquitetura e Urbanismo | Universidade Federal de Viçosa | Av. P. H. Rofls, s/n | Vicosa - MG - Brasil | CEP 36570-000 | Tel.: (31) 3899-2759 | E-mail: natalia.nakamura@ufv.br

Liliane Fernandes Maciel

Arquitetura e Urbanismo | Universidade Federal de Viçosa | E-mail: liliane.maciel@ufv.br

Joyce Correna Carlo

Arquitetura e Urbanismo | Universidade Federal de Viçosa | Tel.: (31) 3899-1982 | E-mail: joycecarlo@ufv.br

Revista Ambiente Construído

Associação Nacional de Tecnologia do Ambiente Construído

Av. Osvaldo Aranha, $99-3^{\circ}$ andar, Centro

Porto Alegre - RS - Brasil

CEP $90035-190$

Telefone: +55 (51) 3308-4084

Fax: +55 (51) 3308-4054

www.seer.ufrgs.br/ambienteconstruido

E-mail: ambienteconstruido@ufrgs.br 